\title{
Aplicação de mapas conceituais como ferramentas didático-pedagógicas na área de recursos e serviços de informação
}

\author{
Maria Giovanna Guedes Farias \\ Gabriela Belmont de Farias \\ Universidade Federal do Ceará - UFC, Brasil
}

\section{ARTICLE}

\begin{abstract}
Resumo
Objetivo. Analisar o uso de mapas conceituais como ferramentas didático-pedagógicas, a partir de uma experiência realizada em sala de aula, nas disciplinas Fontes Especializadas e Serviços de Informação do curso de Biblioteconomia.

Método. A abordagem metodológica caracteriza-se por sua natureza aplicada, exploratória e de observação. Os dados foram coletados junto aos discentes por meio da aplicação de questionário, e a análise ocorreu com auxílio da técnica de análise de conteúdo.

Resultados. A maioria dos alunos veem os mapas conceituais como facilitadores da construção do conhecimento, e visualizam a utilização destes em contextos diversos.

Conclusões. A utilização de mapas conceituais como ferramentas didático-pedagógicas podem promover nos alunos a potencialização do aprendizado e a reflexão sobre o estabelecimento de um percurso para a construção compartilhada de novos saberes, agregando conhecimentos prévios e transformando-os para serem utilizados no preenchimento de lacunas cognitivas.
\end{abstract}

\section{Palavras-chave}

Mapas conceituais ; Ferramentas didático-pedagógicas ; Biblioteconomia ; Recursos e serviços de informação

\section{Application of conceptual maps as didactic and pedagogical tools in the area of resources and information services}

\section{Abstract}

Objective. Analyze the use of concept maps as didactic and pedagogical tools, from an experiment conducted in the classroom, in the disciplines Specialized Sources and Information Services of the graduation in Librarianship.

Method. The methodological approach is characterized by its applied nature, exploratory and observation. Data were collected from the students by applying a questionnaire, and analysis took place with the help of content analysis techniques . Results. The most students see the conceptual maps as facilitators of knowledge construction, and view the use of these in different contexts, like the librarian activities.

Conclusions. The use of concept maps as didactic and pedagogical tools can foster in students the enhancement of learning and reflection on the establishment of a route for the shared construction of new knowledge, adding previous knowledge and transforming them for use in cognitive fill gaps.

\section{Keywords}

Conceptual maps ; Librarianship ; Didactic and pedagogical tools ; Resources and information services 


\section{Introdução}

Os mapas conceituais, considerados ferramentas didático-pedagógicas, possibilitam a representação gráfica do conhecimento e podem auxiliar no processo de ensino-aprendizagem, desde que sua aplicação seja planejada com base nos objetivos que se pretende alcançar, utilizando ainda uma posterior avaliação não apenas da aprendizagem em si, mas do uso dos mapas, em um movimento de experimentação potencial das habilidades da mente, refletindo a respeito do seu próprio pensamento, percebendo e analisando o percurso da aprendizagem, a relação entre os conceitos e palavras, as possibilidades de conexões que a estrutura do mapa pode proporcionar.

Conforme Lima (2013), um mapa conceitual é uma rede cognitiva, na qual os conceitos de um domínio são os nós, e as relações entre eles são indicadas por laços. Essas relações são estabelecidas em função das semelhanças entre os nós, ou seja, conceitos (nós) com características semelhantes encontram-se reunidos na mesma categoria e, por esse motivo, estão unidos por um laço (relação entre conceitos). Esses mapas visam, segundo Belluzzo (2006, p. 85), clarificar ideias em que os sujeitos devem se centrar para uma atividade de busca da solução de problemas, de pesquisa, de tomadas de decisão em organizações, "[...] bibliotecas e serviços de informação, sendo uma atividade mental desenvolvida a partir de uma questão inicial e que tenha significado individual e coletivo."

Esta comunicação apresenta o processo de construção compartilhada do conhecimento, durante uma experiência de utilização de mapas conceituais em atividades das disciplinas fontes especializadas e serviços de informação do curso de Biblioteconomia, tratando ainda dos resultados da avaliação da utilização desta ferramenta pelos alunos, por meio da aplicação de questionários. Esse movimento, de construção compartilhada do conhecimento, ocorre a partir da consciência de que ações devem ser implantadas para e com alunos em uma sala de aula, ou para usuários em uma biblioteca.

Por isso, os pressupostos teóricos do paradigma social da Ciência da Informação (Cl), da mediação da informação, do sócio-interacionismo e a aplicação de mapas conceituais devem ser introjetados durante as atividades de ensino-aprendizagem, bem como no cotidiano laboral do bibliotecário, visando que alunos/futuros profissionais possam potencializar e refletir sobre suas ações, desenvolvendo habilidades necessárias para resolução de problemas diversos.

\section{Construção compartilhada do conhecimento}

Construir de forma compartilhada o conhecimento é, por exemplo, contribuir para o delineamento de uma postura proativa do bibliotecário, o que ocorre durante sua formação e, por conseguinte, nas primeiras experiências profissionais. Um bibliotecário com perfil de mediador, que compreenda sua função entre a informação e o usuário, proporcionando um ambiente favorável ao aprendizado e a apropriação das informações. Dessa forma, entende-se que este profissional deve saber ouvir os usuários; ser tolerante diante dos questionamentos, demonstrando flexibilidade nos mais diversos tipos de consulta, sem emitir juízo de valor, respeitando e estimulando o usuário na continuidade da sua pesquisa; ao formular perguntas e ao respondê-las utilizar linguagem acessível, contribuindo para a solução das dúvidas do usuário, com paciência e criatividade.

Para construir esse perfil profissional, é preciso antes planejar os serviços de informação com base na participação, refletindo nos pressupostos da mediação implícita, que segundo Almeida Júnior (2009), ocorre nos espaços dos equipamentos informacionais em que as ações são desenvolvidas sem a presença física e imediata dos usuários. Conforme Flem (2004), o planejamento participativo prioriza a visão ampla e abrangente decorrente de visões múltiplas, em vez de se deter a uma visão parcial e restrita pela limitação de percepções diversas, conforme quadro 1. 
Quadro 1 - Planejamento convencional versus planejamento participativo

\begin{tabular}{|l|l|}
\multicolumn{1}{|c|}{\begin{tabular}{|c|}
\multicolumn{1}{|c|}{ Planejamento convencional } \\
DE PARA
\end{tabular}} & \multicolumn{1}{c|}{$\begin{array}{c}\text { Planejamento participativo } \\
\text { COM PARA }\end{array}$} \\
\hline Construção imperativa e centralizada & Construção compartilhada e descentralizada \\
\hline Visão parcial e restrita pela limitação de percepções diversas & Visão ampla e abrangente decorrente de visões múltiplas \\
\hline Tecnocrático e economicista & Centrado no social \\
\hline Responsabilidade isolada & Responsabilidade compartilhada \\
\hline Avaliação posterior & Avaliação processual \\
\hline
\end{tabular}

Fonte: FLEM, 2004

Ao construir o conhecimento de forma compartilhada durante a formação do bibliotecário, o professor também atua com o planejamento participativo mediando o aprendizado auxiliando os alunos a aprender, a adquirir, organizar e agir sobre os novos conhecimentos. Como explica Tribus (2001), professor deve ajudar os alunos a construir ferramentas conceituais que Ihes permitam expandir continuamente seu entendimento da experiência individual e coletiva, isso ocorre porque a mediação é interessada em ter 'aprendentes' que dominam seus próprios processos de pensamento, o que pode ser demonstrado quando eles desenvolvem estratégias para controlar a si mesmos quando encontram desafios, confirmando o pensamento de Piaget (1950, p. 35), de que "[...] uma verdade aprendida não é mais que uma meia verdade, enquanto a verdade inteira deve ser reconquistada, reconstruída ou redescoberta pelo próprio aluno."

Uma formação consolidada, baseada na construção compartilhada do conhecimento pode promover a concretização de um perfil de bibliotecário proativo, com foco na satisfação das necessidades dos usuários, ou seja, trata-se de um sistema de informação onde os sujeitos estão conectados, atuando como protagonistas, participantes em todo o processo de formação, consolidação e acesso ao conhecimento. Conforme Feuerstein (1980), o professor/mediador ajuda o 'aprendente' na construção, na experiência da aprendizagem, dotando-se de intencionalidade para possibilitar ao indivíduo transcender aos estímulos e as experiências de vida, respeitando as manifestações culturais de cada realidade, procurando potencializar a aprendizagem com base nas questões/problemas diários dos indivíduos.

Nesse contexto, pode-se empregar a teoria sense-making de Brenda Dervin com o aporte cognitivista e construtivista, utilizando um modelo que destaca a construção de pontes para preencher lacunas e descontinuidades da realidade. De acordo com Dervin (1983), sense-making é um conjunto de conceitos e métodos usados para avaliar como as pessoas constroem sentidos de seus mundos e, em particular, como elas constroem as necessidades e usos de informação nesse processo de tomada/construção de sentido.

Conforme a autora, esta teoria é vista ainda como uma abordagem comportamental de ampla aplicabilidade tanto cognitiva quanto processual, que permite ao indivíduo construir e projetar seu movimento através do tempo-espaço. Gonçalves (2012, p. 9), explica que a intenção sense-making é a de fornecer orientações gerais para que o diálogo seja incentivado em todos os aspectos da comunicação, priorizando "[...] dar voz ao usuário, quando se quer entender as necessidades e usos que estes indivíduos fazem com a informação, permite a criação de uma comunicação dialógica."

Um dos alicerces do sense-making é, como explica Dervin (2003), justamente a suposição de que a realidade não é completa e nem constante, mas sim cheia de descontinuidades ou lacunas fundamentais e penetrantes, até porque todas as coisas não estão conectadas e mudam constantemente. Outro pressuposto do sensemaking é de que a informação não é uma coisa que existe independente e externa aos seres humanos, mas sim um produto da observação humana, o que pode ser aplicado tanto às observações "diretas" da realidade, quanto às observações das observações feitas por outros. Inicialmente, a abordagem do sense-making não tinha como foco as dimensões coletivas do processo de construção de sentido, não enfatizava o indivíduo e seu mundo interno. Porém, a partir do início da década de 90 Dervin:

[...] tenta superar essa visão individualista, direcionando sua atenção para fatores mais sociais, como o contexto e o sense-making coletivo. Como exemplo dessa tendência, a metodologia passou a destacar a verbalização (verbing) - utilização, pelo entrevistado, de verbos em vez de substantivos - para a caracterização da situação vivenciada pelo indivíduo no processo de construção de sentido. Ao superar a antiga ênfase dada ao substantivo, Dervin [...] realça a importância da ação descrita pelo verbo, agora construída na linguagem (construção coletiva e social). A ênfase passa a estar nas ações e movimentos realizados 
pelos indivíduos, que revelam na linguagem as motivações cognitivas e emocionais durante o processo de busca de informação e procuram solucionar o problema vivido (gap). (VENÂNCIO; NASSIF, 2008, p. 98).

Após superar esta visão individualista descrita acima, Dervin implementou a abordagem do sense-making direcionada para fatores mais sociais, a qual pode ser utilizada em projetos de pesquisa, durante o planejamento de ações como o uso de mapas conceituais em sala de aula, na elaboração de serviços de informação em bibliotecas, usando um modelo constituído pelos seguintes elementos, apresentados na Figura 1: contexto (culturas e comunidades, sistemas de conhecimento de domínio e estrutura de poder e dinâmica), resultados (ajudas, obstáculos, funções, disfunções, consequências, impactos, efeitos, horizontes futuros), ponte (ideias, cognições, pensamentos, atitudes, crenças, valores, sentimentos, emoções, intuições, memórias, estórias e narrativas), verbalização (construir sentido, desfazer sentido), situação (histórias, experiências, identidades, horizontes passados, horizontes presentes, barreiras e restrições) e lacuna (questões, perturbações, confusões, enigmas, ansiedade) no espaço e no tempo.

Figura 1 - Current Sense-Making model

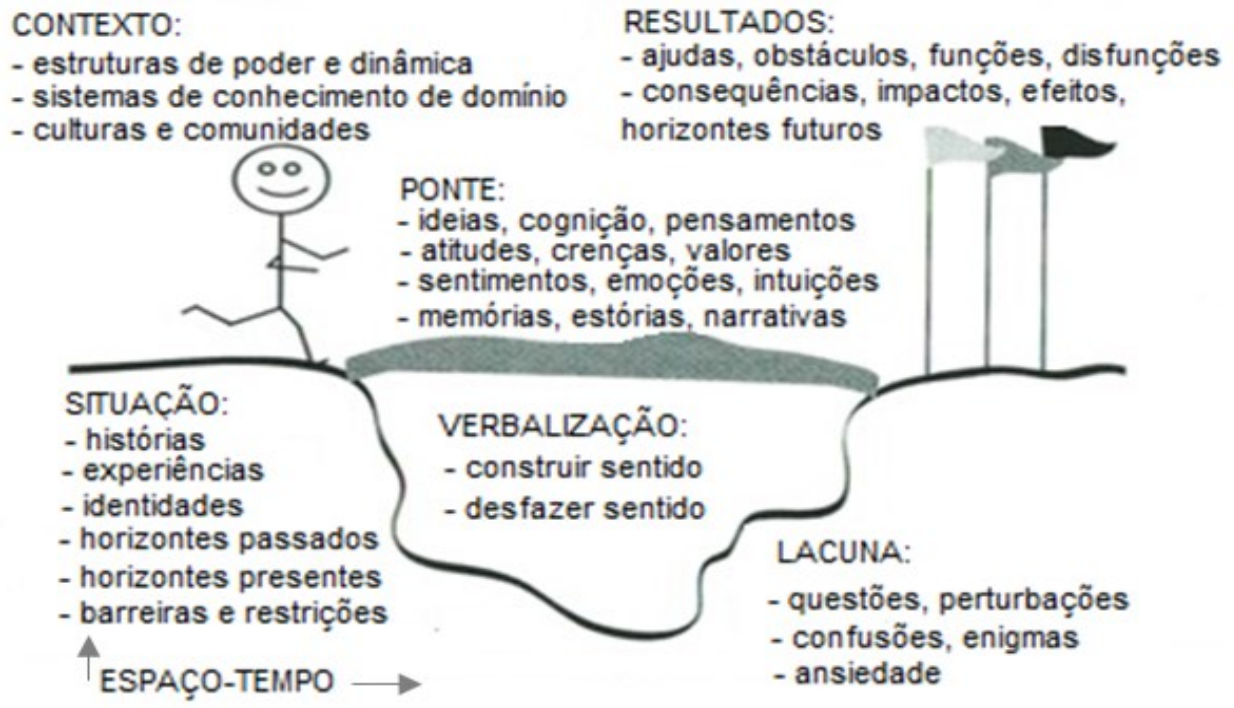

Fonte: Dervin (1999, tradução nossa).

Para explicar o atual modelo de sense-making de Dervin, é utilizada a interpretação de Venâncio e Nassif (2008, p. 98), que descrevem primeiramente o estado cognitivo do indivíduo "[...] representado metaforicamente como um movimento contínuo, no tempo e no espaço, no qual o próprio indivíduo cria sentido para suas ações e para o ambiente." Os autores esclarecerem que, nessa trajetória surgem constantemente situações problemáticas, tentando impedir o indivíduo de prosseguir devido à percepção de um vazio cognitivo, por isso, para superá-lo ele tenta compreender tal vazio baseado na interpretação resultante determina estratégias. Em resumo, a teoria do sense-making enfatiza:

[...] as situações experienciadas pelos indivíduos em um contexto temporal e espacial, no qual surgem as necessidades de informação, influenciadas pela experiência e pelas histórias de vida do indivíduo; os gaps cognitivos enfrentados (necessidades de informação, questões que as pessoas têm quando constroem sentido e movem-se através do tempo-espaço) que são representados pelas angústias, desordens e confusões; o uso da informação, ou seja, as pontes ou estratégias construídas (ideias, pensamentos, atitudes) para superação dos gaps. (VENÂNCIO; NASSIF, 2008, p. 98).

As reflexões provocadas pelo modelo de Dervin demonstram a necessidade da construção de pontes para superar o vazio cognitivo causado por situações adversas, provocando lacunas que tentam impedir o sujeito de 
prosseguir, e por isso os alunos precisam saber como aprender, como selecionar o que conhecer, como compreender fatos e fenômenos, como estabelecer suas relações interpessoais, como analisar, refletir e agir sobre esta nova ordem das coisas, ou seja, é preciso como afirma Torres (2007): aprender a conhecer, a ser, a fazer e a conviver.

Ainda segundo a autora, é preciso ativar nossos esquemas mentais, mobilizar conhecimentos prévios, transformando-os ou atualizando-os em função daquilo que é novo a cada situação, quer seja no âmbito de nossas relações sociais, pessoais ou afetivas, quer seja na realização de tarefas profissionais ou de outra natureza qualquer, e ainda selecionando ações ou procedimentos que consideramos os melhores naquele momento. "Dados e informações articulam-se para criar obstáculos que momentaneamente provocam perturbação cognitiva no aluno, o qual exercerá o papel de leitor da realidade que o cerca". Nesse contexto de desafio, o aluno deverá mobilizar recursos cognitivos e conhecimentos anteriormente adquiridos, "[...] reorganizando-os, criando novas ideias e construindo uma linha de argumentação durante o processo de enfrentamento e resolução da questão proposta." (TORRES, 2007, p.33).

A teoria de aprendizagem significativa pode ajudar neste processo, ao disponibilizar para os alunos mecanismos cognitivos com potencial de vincular à informação armazenada às informações novas, gerando assim, um conhecimento que colabore efetivamente para atender as necessidades sociais de cada indivíduo.

\section{Aprendizagem significativa}

As ideias do psicólogo cognitivista David Ausubel tiveram início na década de 60 e "[...] encontram-se entre as primeiras propostas psicoeducativas que tentam explicar a aprendizagem escolar e o ensino, a partir de um marco distante dos princípios condutistas." (PELIZZARI; et al. 2002, p.38). Ausubel propõe-se a estudar o ato da formação de significados ao nível da consciência, ou seja, da cognição - fenômeno mediante o qual o mundo de significados tem origem na:

Psicologia cognitivista, que se preocupa com o processo da compreensão, transformação, armazenamento e uso da informação envolvida na cognição, e tem como objetivo identificar os padrões estruturados dessa transformação. É uma teoria particular, cuja asserção central é a de que ver, ouvir, cheirar etc., assim como lembrar, são atos de construção que podem fazer maior ou menor uso dos estímulos externos, dependendo da circunstância, isto é, das condições pessoais de quem realiza o processo. (MOREIRA; MASINI, 2001, p.13).

A aprendizagem está subordinada a um esforço do aprendiz em ligar seus novos conhecimentos aos seus conhecimentos anteriores. Para Ausubel (1968) a aprendizagem significativa requer organização e integração do material na estrutura cognitiva, entendida como "[...] conteúdo total de ideias de certo indivíduo e sua organização; ou conteúdo e organização de suas ideias em uma área particular de conhecimento" (AUSUBEL, 1968, p.37-38). A Teoria de Ausubel também tem raiz na Psicologia Educacional, que ele define como:

[...] uma ciência aplicada que tem um valor social, interessada não em leis gerais da aprendizagem em si mesmas, mas em propriedades de aprendizagem, que possam ser relacionadas a meios eficazes de deliberadamente levar a mudanças na estrutura cognitiva. (AUSUBEL, 1968, p.8).

Sua teoria enfoca a aprendizagem cognitiva, resultante do armazenamento organizado de informações na mente do ser que aprende. Na aprendizagem, entretanto, é imprescindível considerar o contexto social, cultural e econômico em que o aluno está inserido, criando condições que possibilitem a aprendizagem significativa, pois:

Lida com pessoas num contexto social, respeitando seus significados, e não com leis abstratas gerais de aprendizagem; e dá condições para que as pessoas participem ativamente de seu processo de aprendizagem e colaborem de forma consciente para as necessidades sociais que passam a perceber. (MOREIRA; MASINI, 2001, p.94). 
Ao contrário da aprendizagem mecânica ou repetitiva - que nada mais é do que a aquisição de informações com pouca ou nenhuma associação a conceitos relevantes na estrutura cognitiva, à qual as atribuições e associações de significados são incorporadas arbitrariamente na estrutura cognitiva - a aprendizagem significativa traz uma abordagem, em que a pessoa adquire novas estruturas de conhecimento pela incorporação de novos conteúdos, com suporte na relação com seu conhecimento prévio (PELIZZARI; et al. 2002).

Na perspectiva de Ausubel (1968), há duas condições para haver aprendizagem significativa: a primeira está relacionada à disposição de apreender, por parte do aluno; a segunda vincula-se à potencialidade significativa do conteúdo a ser estudado. Assim,

Com esse duplo marco de referência, as proposições de Ausubel partem da consideração de que os indivíduos apresentam uma organização cognitiva interna baseada em conhecimentos de caráter conceitual, sendo que a sua complexidade depende muito mais das relações que esses conceitos estabelecem em si que do número de conceitos presentes. Entende-se que essas relações têm um caráter hierárquico, de maneira que a estrutura cognitiva é compreendida, fundamentalmente, como uma rede de conceitos organizados de modo hierárquico de acordo com o grau de abstração e de generalização (PELIZZARI; et al. 2002, p.38).

A aprendizagem significativa tem sua dimensão na estrutura de aprendizagem por descoberta, ou seja, essa dimensão está relacionada à maneira como os conteúdos são recebidos pelo aluno. Esses conteúdos deverão ser administrados de modo que não haja um formato final ou acabado, pois o aluno, antes de assimilá-los, deverá articular em sua estrutura cognitiva o conteúdo preestabelecido com o novo de maneira substancial, possibilitando a ele encontrar novos caminhos para resolução de problemas. As vantagens da aprendizagem significativa são essencialmente três, sendo elas:

\begin{abstract}
Em primeiro lugar, o conhecimento que se adquire de maneira significativa é retido e lembrado por mais tempo. Em segundo, aumenta a capacidade de aprender outros conteúdos de uma maneira mais fácil, mesmo se a informação original for esquecida. E, em terceiro, uma vez esquecida, facilita a aprendizagem seguinte - a "reaprendizagem", para dizer de outra maneira (PELIZZARI et al., 2002, p.39-40).
\end{abstract}

As vantagens citadas são intrínsecas ao processo central da aprendizagem significativa contribuindo, a interação da estrutura cognitiva prévia do aluno com o conteúdo de estudo. Essa interação refere-se a um processo de modificação mútua, tanto da estrutura cognitiva inicial quanto do conteúdo que é preciso aprender, ou seja, o aluno permanece constantemente na aprendizagem. Esses princípios, conforme Belluzzo (2007), também norteiam o desenvolvimento da competência em informação (Colnfo), uma vez que esta última envolve o reconhecimento de uma necessidade de informação, o acesso e uso de forma inteligente, comparando-a com o conhecimento prévio e procurando a elaboração de um conhecimento, no qual a modificação da estrutura cognitiva é fator primordial para uma aprendizagem efetiva e para os resultados esperados.

Com o intuito de aperfeiçoar a aquisição de um corpo organizado de conhecimentos e na permanência de ideias inter-relacionadas, Ausubel (1968) estabelece a ideia de que uma aprendizagem significativa ocorre quando uma nova informação interage com a composição de conhecimento específico (estrutura de conhecimento específico é definida pelo autor como subsunçora), existente na estrutura cognitiva da pessoa. Para Ausubel, a estrutura cognitiva é formada por uma hierarquia de conceitos (subsunçores), que são abstrações da experiência humana. "A aprendizagem só é significativa se o conteúdo descoberto relacionar-se a conceitos subsunçores relevantes já existentes na estrutura cognitiva” (MOREIRA; MASINI, 2001, p.19).

Os elementos subsunçores são facilitadores do ato de aprender. São elementos representados pelo conhecimento prévio e por conceitos anteriormente formulados pelo aprendiz. Também, podem ser considerados como elementos subsunçores aqueles utilizados pelo docente para auxiliar na organização do conhecimento a ser constituído pelo aluno. Nesse sentido, os materiais, explanações introdutórias e toda a gama de atividades voltadas para a elaboração de uma ideia inicial sobre algum conteúdo podem ser 
considerados elementos subsunçores, contanto que atuem, de fato, como facilitadores da aprendizagem (BESSA, 2008).

Outro elemento recomendado por Ausubel são os organizadores prévios, que servem de âncora para a nova aprendizagem e levam ao desenvolvimento de conceitos subsunçores que facilitam a aprendizagem subsequente. Os organizadores prévios são materiais introdutórios mostrados antes do próprio material a ser aprendido. Eles servem de ponte entre o que o aprendiz já sabe e o que ele deve saber. "Os organizadores prévios são úteis para facilitar a aprendizagem, na medida em que funcionam como "pontes cognitivas" (MOREIRA; MASINI, 2001, p.21). Isto porque, para esses autores, os organizadores permitem promover uma moldura ideacional para incorporação e retenção do material.

Observa-se que a proposta de David Ausubel em relação aos organizadores é uma estratégia de preparação da estrutura cognitiva, a fim de facilitar a aprendizagem significativa. $O$ autor sugere alguns métodos para o desenvolvimento desta aprendizagem, como a solução de problemas, diferenciação de ideias relacionadas aos conceitos subsunçores aprendidos e atividades de aprendizagens sequenciais dependentes uma da outra, que não podem ser executadas sem um perfeito domínio da precedente.

$\mathrm{Na}$ aprendizagem significativa, além da elaboração dos conceitos subsunçores é também possível uma ocorrência de interações desses conceitos elaborados e sua diferenciação em decorrência de sucessivas interações. Também há que ser considerada a reconciliação integrativa na programação de conteúdo, explorando as relações entre proposições e conceitos, chamando a atenção para diferenças e similaridades importantes e reconciliar inconsistências reais ou aparentes.

Ausubel (1968) sustenta a ideia de que cada disciplina acadêmica tem uma estrutura articulada e hierarquicamente organizada de conceitos, o que constitui o sistema de informações dessa disciplina. Ele sugere a utilização de mapas conceituais para refletir a organização de uma disciplina ou parte de uma disciplina. Nessa perspectiva, vislumbra-se a possibilidade de desenvolver a Colnfo por meio da estrutura teórico-conceitual das disciplinas.

\section{Mapas conceituais: ferramentas didático-pedagógicas}

Os mapas conceituais podem ser pensados como ferramentas para negociar significados, pois conforme Novak e Gowin (1999), são representações explícitas e abertas de conceitos e proposições, e permitem que docentes e alunos compartilhem significados. Segundo os autores, essas ferramentas se constituem em dispositivos esquemáticos para representar um conjunto de significados de conceitos encaixados em um sistema de referência proposicional. A utilização de mapa conceitual possibilita vantagens e desvantagens como explicam Moreira e Masini (2001, p.57):

\footnotetext{
Possíveis vantagens: Enfatizar a estrutura conceitual de uma disciplina e o papel dos sistemas conceituais no seu desenvolvimento; Mostrar que os conceitos de uma certa disciplina diferem quanto ao grau de inclusividade e generalidade, e apresentar esses conceitos numa ordem hierárquica de inclusividade que facilite a aprendizagem e a retenção dos mesmos; Prover uma visão integrada do assunto e uma espécie de "listagem" daquilo que foi abordado nos materiais instrucionais. Possíveis desvantagens: Se o mapa não tiver significado para os alunos, eles poderão encará-lo apenas como algo mais a ser memorizado; Os mapas podem ser muito complexos ou confusos, dificultando a aprendizagem e a retenção, ao invés de facilitá-las; A habilidade dos alunos para construir suas próprias hierarquias conceituais pode ficar inibida, em função do fato de que já recebem prontas as estruturas propostas pelo docente (segundo sua própria percepção e preferência).
}

Para planejar instrumentos que facilitem a aprendizagem significativa é indispensável uma compreensão de dois aspectos: o primeiro é a organização e integração dos conceitos e proposições unificadores de uma dada disciplina, além da coordenação e integração do assunto em vários níveis; o segundo elemento está relacionado aos princípios programáticos adequados à ordenação da sequência do assunto, "[...] partindo do estabelecimento de sua organização e lógica interna e, sucessivamente, planejando a montagem de exercícios práticos" (MOREIRA; MASINI, 2001, p.48). 
A programação do conteúdo que facilite a aprendizagem significativa segue quatro princípios estabelecidos por Ausubel (1968), sendo eles: diferenciação progressiva, reconciliação integrativa, organização sequencial e consolidação. Os dois primeiros já foram abordados. A organização sequencial está relacionada à disposição da sequência das ideias-âncora da disciplina, enquanto a consolidação está relacionada à perpetuação do que está sendo estudado, assegurando a continuidade do material de ensino e sucesso na aprendizagem. A Figura 2 elucida o modelo instituído pela teoria de Ausubel.

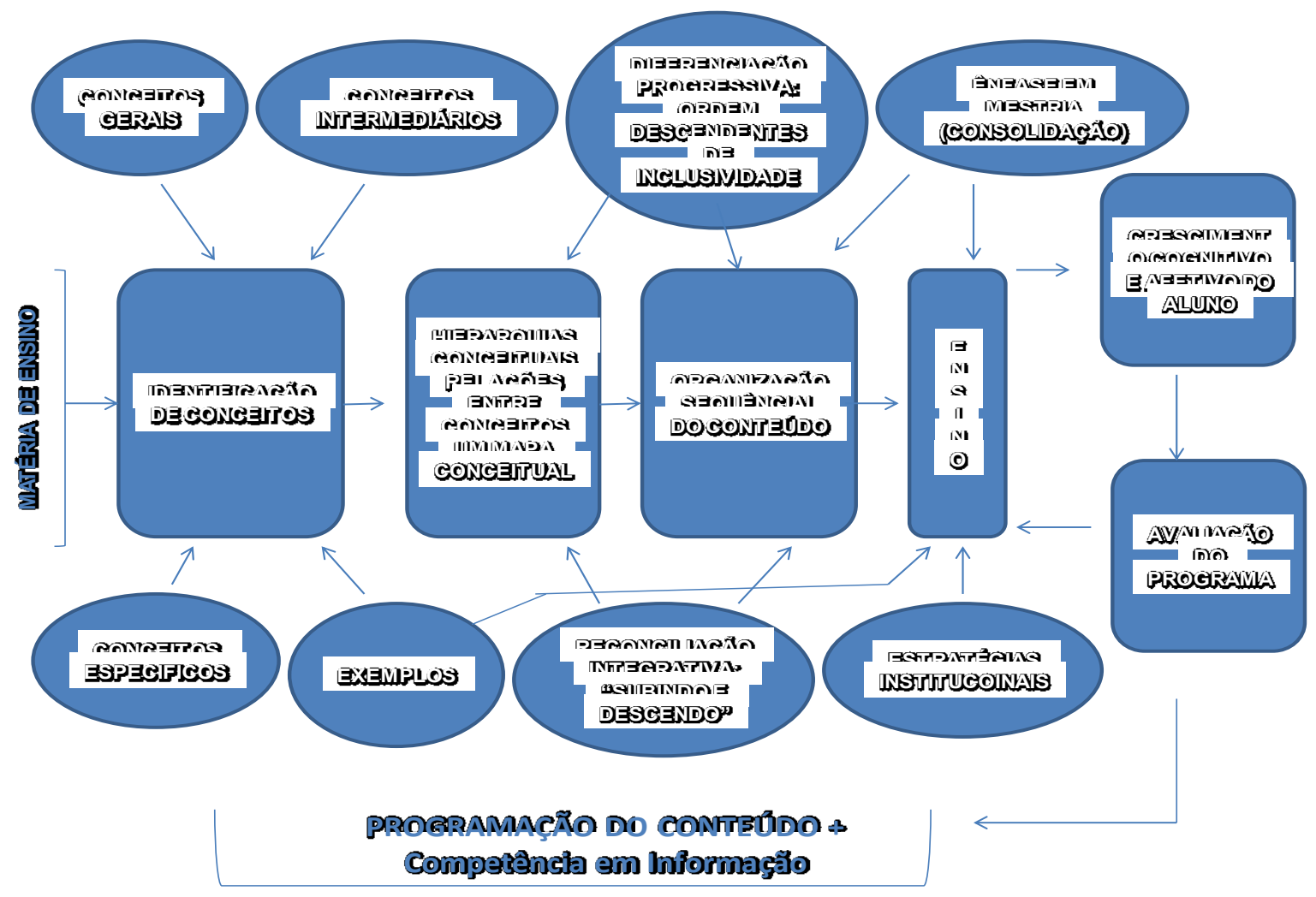

Fonte: Adaptado de Moreira e Masini (2001, p.49).

Este modelo prioriza a identificação dos conceitos e as relações hierárquicas entre eles, sequenciando o conteúdo em ordem descendente, tirando vantagem das dependências sequenciais naturais entre os tópicos, com ênfase no conhecimento preexistente do aluno e o uso de organizadores como pontes cognitivistas. Implica organizar e integrar os conceitos e proposições da disciplina, programando o conteúdo de forma lógica e conectado a um encadeamento de ações que desenvolva assimilação do novo conhecimento ao preexistente por via de exercícios práticos. Tornando visível o encadeamento das ideias-âncora da disciplina, consolidando o estudo e assegurando a continuidade do ensino-aprendizagem. Recomenda-se sua aplicação à formação básica do bibliotecário, considerando-se que esse modelo potencializa a capacidade de aprender e pensar do aluno, permitindo ser mais crítico em relação ao seu desempenho perante a sociedade.

Como é possível observar, Ausubel formula uma teoria de aprendizagem extensa e complexa, que tem como base "[...] a questão da significação do mundo por meio da organização dos conhecimentos em esquemas cognitivos." (BESSA, 2008, p.136). A falta de compreensão à lógica da proposição da Teoria de Ausubel pode ser um motivo para pouca utilização da Teoria da Aprendizagem Significativa por parte dos profissionais da educação.

Por outro lado, entretanto, se os docentes compreenderem as contribuições dos processos de aquisição de conhecimento e fixação de conteúdos trazidos da Teoria de Ausubel, acredita-se que seja possível praticar em sala de aula estilos de intervenção que auxiliem a facilitação da aprendizagem de forma significativa, para que os alunos ganhem autonomia na aprendizagem dos próprios conceitos e seus caminhos. Para tanto, é 
necessário determinar a estrutura conceitual e proposicional da matéria; identificar os elementos subsunçores necessários para aprender significativamente um conteúdo; diagnosticar os subsunçores disponíveis na estrutura cognitiva do aluno; e ensinar utilizando recursos e princípios que conduzem os estudantes a uma aprendizagem significativa (AUSUBEL, 2003).

Com efeito, pode-se perceber que o docente, ao desenvolver um conteúdo teórico-prático, deve organizar recursos que venham agregar informação ao conhecimento preexistente do aluno, requisitos pertinentes aos princípios da Colnfo. Sua transposição às práticas de ensino-aprendizagem nos cursos de Biblioteconomia e, em especial, em disciplina que desenvolva competência em informação, certamente, reunirá as condições de auxiliar a pensar e a manter as conexões entre conceitos e sua estrutura, o que facilitará e extrapolará a informação apreendida a outra situação de uma realidade, permitindo, ainda, tornar o aprendizado real e ao longo da vida, proceder às inter-relações em vários campos do conhecimento. Ao abordar a relevância do desenvolvimento da competência na formação do bibliotecário, acredita-se que, além de utilizar a Teoria de David Ausubel, há a necessidade da complementaridade com a abordagem teórica, conceitual e pragmática da Colnfo.

\section{Percurso metodológico}

A pesquisa caracteriza-se por sua natureza aplicada, exploratória e de observação, além de possuir uma revisão bibliográfica relacionada à teoria do mapa conceitual, desenvolvida por Novak (1984) a partir da Teoria da Aprendizagem de David Ausbel. Assume a forma de uma pesquisa-ação, pois conforme Thiollent (1997, p. 15), este tipo de pesquisa "consiste essencialmente em acoplar pesquisa e ação em um processo, no qual os atores implicados participam, junto com os pesquisadores, para chegarem interativamente a elucidar a realidade em que estão inseridos". Para Lewin (1965, p. 177), a pesquisa-ação caracteriza-se pelos seguintes elementos:

[...] análise, evidência e conceitualização sobre problemas; planejamento de programas de ação, executando-os e então mais evidências e avaliação; e então a repetição de todo esse círculo de atividades; certamente, uma espiral de tais círculos. Por meio dessa espiral de círculos, a pesquisa-ação cria condições sobre as quais comunidades de aprendizagem podem ser estabelecidas, ou seja, comunidades de investigadores comprometidos com a aprendizagem e compreensão de problemas e efeitos de sua própria ação estratégica e de fomento dessa ação estratégica na prática.

Na América Latina, a pesquisa-ação também foi formulada em termos de "pesquisa participante", sendo utilizada como instrumento no contexto das populações carentes, "com seus problemas educacionais, culturais ou de consciência política" (Thiollent, 1997, p. 65), e no Brasil tem sido pensada e aplicada no contexto das organizações e instituições:

Um tipo de pesquisa social com base empírica que é concebida e realizada em estreita associação com uma ação ou com a resolução de um problema coletivo e no qual os pesquisadores e os participantes estão envolvidos de modo cooperativo ou participativo. (THIOLLENT, 2000, p. 14)

No caso desta pesquisa, pesquisadores e participantes se envolveram para cooperativamente refletir e agir sobre a potencialização do aprendizado, com vistas a construir de forma compartilhada novos saberes, por meio de uma ferramenta didático-pedagógica.

Participaram da pesquisa 38 discentes do curso de Biblioteconomia da Universidade Federal do Ceará (UFC) sendo 22 da disciplina Fontes Especializadas (ministrada no quarto semestre) e 16 da disciplina Serviços de Informação (ministrada no sétimo semestre). Ao iniciar a atividade foi ministrada uma aula tendo como conteúdo "O Mapa Conceitual como Instrumento de Ensino-Aprendizagem", no qual teve como objetivo apresentar aos alunos a aplicação do mapa conceitual na rotina de análise e leitura de artigos, textos, capítulo de livros entre outros elementos. O segundo momento da atividade ocorreu com a indicação de leitura de um artigo científico- 
teórico-conceitual, que aborda os princípios e fundamentos das disciplinas já mencionadas e outros para serem apresentados como seminários.

Para coletar os dados, se fez uso de um questionário com questões abertas e fechadas, visando atingir o objetivo de analisar o uso de mapas conceituais como ferramentas didático-pedagógicas em um processo de construção compartilhada do conhecimento. A análise dos dados respaldou-se na tabulação do questionário e das anotações das duas docentes pautadas nas observações realizadas em sala de aula.

Já para analisar os dados, empregou-se a técnica de análise de conteúdo (AC) de Bardin (2009), um conjunto de instrumentos metodológicos em constante aperfeiçoamento, que se aplicam a 'discursos' diversificados, por oscilar entre o rigor da objetividade e da fecundidade da subjetividade, e por atrair o investigador pelo escondido. Gomes (1994, p. 74) em consonância com Bardin, explica que uma das funções da AC é a "[...] descoberta do que está por trás dos conteúdos manifestos, indo além das aparências do que está sendo comunicado."

Procedeu-se com uma leitura flutuante dos questionários, preparando e explorando o material para trata-lo, interpretando-o, e após estabeleceu-se as seguintes categorias de análise: mapas conceituais como facilitadores da construção do conhecimento; desafios na construção dos mapas conceituais; aceitação da metodologia de ensino; e utilização dos mapas em contextos diversos, a exemplo das atividades do bibliotecário. Tais categorias são analisadas a seguir conforme os preceitos da análise de conteúdo.

\section{Análise e discussão dos resultados}

As informações coletadas foram organizadas baseadas na técnica de análise de conteúdo, onde criou-se categorias de respostas produzidas conforme as categorias do questionário aplicado aos alunos, a fim de facilitar o trabalho durante a análise dos dados. Analisar na visão de Queiroz (1991, p. 05) "[...] significa decompor um texto, fragmentá-lo em seus elementos fundamentais, isto é, separar claramente os diversos componentes, recortá-los, a fim de utilizar somente o que é compatível com a síntese que se busca". Esse é também o momento de descobertas, de interpretações, de analisar o não dito, de fazer com que as falas dialoguem entre si e com os personagens envolvidos neste processo de desnudamento dos conhecimentos por eles transmitidos.

A categoria Mapas conceituais como facilitadores da construção do conhecimento teve como objetivo, identificar se houve compreensão do conteúdo trabalhado em sala de aula, bem como se os mapas se caracterizam como potenciais instrumentos de aprendizagem. Os dados coletados, conforme a Tabela 1, demonstram que $92,1 \%$ dos alunos afirmaram ter compreendido o conteúdo trabalhado em sala de aula, enquanto $7,9 \%$ tiveram algum tipo de dificuldade no entendimento do texto por meio da elaboração do mapa.

Tabela 1 - Mapas conceituais como facilitadores da construção do conhecimento

\begin{tabular}{l|r|r}
\multicolumn{1}{c|}{ Disciplinas } & \multicolumn{1}{|c|}{ Sim } & \multicolumn{1}{c}{ Não } \\
\hline Fontes Especializadas & 20 & 2 \\
\hline Serviços de Informação & 15 & 1 \\
\hline Total & 35 & 3 \\
\hline Percentual total & $92,1 \%$ & $7,9 \%$
\end{tabular}

Fonte: Dados da pesquisa, 2015

Em relação à percepção do mapa enquanto instrumento de aprendizagem, todos os alunos participantes da pesquisa responderam positivamente sobre a aplicabilidade do uso do mapa como ferramenta de aprendizagem. Destarte, os dados acima estão em consonância com as reflexões de Moreira e Masini (2001), quando afirmam que os alunos ao utilizarem mapas conceituais, conseguem compreender a estrutura conceitual de uma 
disciplina, pois esta ferramenta facilita a aprendizagem e a retenção de novos conhecimentos, além de prover uma visão integrada do assunto abordado em sala de aula.

Em relação ao percentual (7,9\%) que respondeu ter dificuldade na compreensão do conteúdo ao elaborar o mapa, se faz necessário um olhar mais atento do docente para compreensão do déficit de aprendizagem desses alunos, pois segundo Moreira e Masini (2001, p. 57) "se o mapa não tiver significado para os alunos, eles poderão encará-lo apenas como algo mais a ser memorizado". Dessa forma, é preciso haver uma intervenção direcionada por parte do professor visando solucionar as deficiências, possibilitando o nivelamento dos alunos em relação aos demais, ao construir o conhecimento de forma compartilhada com planejamento participativo, mediando o aprendizado e auxiliando os alunos a aprender, a adquirir, organizar e agir sobre os novos conhecimentos. Segundo Tribus (2001), o professor deve ajudar os alunos a construir ferramentas conceituais que Ihes permitam expandir continuamente seu entendimento da experiência individual e coletiva.

A categoria Desafios na construção dos mapas conceituais visou observar as dificuldades encontradas pelos alunos no momento da construção dos mapas conceituais, as quais eles identificaram como sendo: definir a questão local; ligar corretamente os conceitos; encontrar termos; falta de prática; identificar os conceitos principais e saber interliga-los; sintetizar as informações e ideias para inserir no mapa, de forma que contemplasse todo o conteúdo do texto; organizar as informações e ideias de diferentes textos; definir os tópicos partindo do mais geral para o mais específico; e organização estética e de espaço.

Observa-se que os desafios apontados estão relacionados à falta de ordenamento/planejamento estrutural das ideias, um processo cognitivo que se torna explícito durante a construção dos mapas, os quais, segundo Moreira e Massini (2001), precisam de uma organização e lógica interna e de exercícios práticos. Nessa perspectiva, os docentes têm um papel fundamental que é o de estimular os alunos a se tornarem protagonistas do seu próprio processo de aprendizagem, pois como explica Feuerstein (1980), o professor ajuda o 'aprendente' na construção, na experiência da aprendizagem, dotando-se de intencionalidade para possibilitar ao indivíduo transcender os estímulos e as experiências de vida, respeitando as manifestações culturais de cada realidade, procurando potencializar a aprendizagem com base nas questões/problemas diários dos indivíduos.

A categoria Aceitação da metodologia de ensino evidenciou que a maioria dos alunos (86,8\%) gostou da didática de construção de mapas, enquanto o percentual de $13,2 \%$ não se identificou com a atividade, conforme dados da Tabela 2. Essa porcentagem leva à reflexão de que, a abordagem trabalhada em sala de aula, pode não ter sido adequada para o entendimento total do aluno a respeito dessa didática. Já o percentual de aceitação demonstra que a metodologia é viável de ser aplicada, pois mesmo com as dificuldades descritas na categoria "Desafios na construção dos mapas conceituais", percebe-se que a utilização dos mapas conceituais se constitui, conforme Ausubel (2003), em uma intervenção que auxilia a aprendizagem de forma significativa.

Tabela 2 - Aceitação da metodologia de ensino

\begin{tabular}{l|r|r}
\multicolumn{1}{c|}{ Disciplinas } & \multicolumn{1}{c|}{ Sim } & \multicolumn{1}{c}{ Não } \\
\hline Fontes Especializadas & 20 & 3 \\
\hline Serviços de Informação & 13 & 2 \\
\hline Total & 33 & 5 \\
\hline Percentual total & $86,8 \%$ & $13,2 \%$
\end{tabular}

Fonte: Dados da pesquisa, 2015

O percentual de alunos que não se identificou com a metodologia de ensino, leva o docente a planejar ações, visando diagnosticar os motivos pelos quais os alunos não aceitam a didática aplicada em sala de aula. Só a partir desse diagnóstico, é que se pode evidenciar de fato, quais as variáveis que impedem esses alunos a se identificarem com a metodologia.

A categoria Utilização dos mapas em contextos diversos, a exemplo das atividades do bibliotecário objetivou perceber se os alunos vislumbram a aplicabilidade da construção de mapas conceituais em outro tipo de atividade além da acadêmica, 92,1\% responderam que sim, enquanto 7,9\% responderam não, conforme Tabela 3. 
Tabela 3 - Utilização dos mapas em contextos diversos

\begin{tabular}{l|r|r}
\multicolumn{1}{c|}{ Disciplinas } & \multicolumn{1}{|c|}{ Sim } & \multicolumn{1}{c}{ Não } \\
\hline Fontes Especializadas & 20 & 2 \\
\hline Serviços de Informação & 15 & 1 \\
\hline Total & 35 & 3 \\
\hline Percentual total & $92,1 \%$ & $7,9 \%$
\end{tabular}

Fonte: Dados da pesquisa, 2015

Os discentes que responderam positivamente sobre a utilização dos mapas conceituais em outros contextos, deram como exemplo: auxílio no planejamento da unidade de informação e do gestor, na divulgação do acervo e dos serviços e produtos de informação; criação de fluxos operacionais mais contextualizados com as realidades de vida dos usuários; planejamento do gestor, na divulgação dos serviços ao usuário; construção de projetos; organizar, representar e compartilhar o conhecimento no ambiente organizacional assimilando boas práticas; auxiliar no processo de indexação e catalogação do item informacional; no processo de escolha dos títulos para aquisição do acervo; mapear as competências dos funcionários visando a eficácia na gestão de pessoas; enfim, em todas as atividades desenvolvidas em uma biblioteca e os seus diversos setores, como o de referência, empréstimo e devolução e gestão da mesma.

Essa percepção da maioria dos alunos, em relação à utilização dos mapas em contextos diversos, demonstra que eles conseguem mobilizar conhecimentos prévios, transformando-os ou atualizando-os em função daquilo que é novo a cada situação, quer seja no âmbito de nossas relações sociais, pessoais ou afetivas, quer seja na realização de tarefas profissionais ou de outra natureza qualquer, e ainda selecionando ações ou procedimentos que consideram os melhores naquele momento, como ressalta Tribus (2007).

Em relação ao percentual de alunos que não veem a utilização dos mapas em contextos diversos, pode-se inferir que alguns obstáculos provocam perturbação cognitiva no discente, as quais podem ser solucionadas ao implantar as estratégias/ações acima apresentas em outras categorias. Destarte, neste contexto corrobora-se com Torres (2007), ao refletir que os alunos precisam saber como aprender, como selecionar o que conhecer, como compreender fatos e fenômenos, como estabelecer suas relações interpessoais, como analisar, refletir e agir sobre esta nova ordem das coisas.

\section{Conclusão}

Ao utilizar mapas conceituais como ferramentas didático-pedagógicas para auxiliar no processo de ensinoaprendizagem, em atividades na sala de aula, visando representar o conhecimento, compreendeu-se que todas as experiências vivenciadas com os alunos devem ser posteriormente avaliadas, pensando-se em construir um conhecimento compartilhado, com e para os discentes, considerando as características do grupo com que se trabalha e o percurso da aprendizagem.

Mesmo que a maior parte dos alunos pesquisados tenha apontado como positiva a aplicabilidade do uso do mapa, como ferramenta que facilita a aprendizagem, e não tenha tido dificuldades na elaboração, é preciso ponderar sobre o percentual de discentes que não obteve o mesmo êxito. É necessário que o docente atue realmente como mediador, propiciando um ambiente em que o estímulo ao empoderamento do conhecimento que está sendo disseminado em sala de aula seja constante, para que o aluno possa caminhar em direção a se tornar protagonista do seu próprio processo de aprendizagem.

Nesta perspectiva, deve-se considerar, por exemplo, barreiras encontradas pelos alunos em atividades desenvolvidas em sala de aula, a exemplo da construção dos mapas conceituais, onde observou-se que os obstáculos encontrados centram-se na falta de ordenamento das ideias, ou seja, na ausência de um planejamento. Sabendo disso, o docente pode estimular o aluno na construção do processo de aprendizagem, respeitando sua realidade e suas experiências de vida. 
É necessário refletir que um dos primeiros passos para a mediação numa concepção de construção do conhecimento é questionar e redefinir os papéis dos sujeitos na educação, para que o docente, enquanto mediador desse processo possa analisar sua práxis pedagógica, construindo novas possibilidades de aprendizagem. Pois, enquanto autores e atores fundamentais à mudança educacional que se busca, é necessário que se possa ter múltiplas atuações, não só com a informação científica precisa e atualizada, mas, também, com todas as competências estruturantes do pensamento e da ação que intentam desenvolver nos próprios alunos. Para isso, é preciso selecionar estratégias pedagógicas que possibilitem o desenvolvimento de competências que tornem o aluno um sujeito pensante, ativo e crítico sobre seu percurso de aprendizagem.

Desta forma, conclui-se que a utilização dos mapas conceituais pode promover nos alunos a potencialização do aprendizado e a reflexão sobre o estabelecimento de um percurso para a construção compartilhada de novos saberes, agregando conhecimentos prévios e transformando-os para serem utilizados no preenchimento de lacunas cognitivas.

\section{Referências}

ALMEIDA JÚNIOR, O. F. de. Mediação da informação e múltiplas linguagens. Pesquisa Brasileira em Ciência da Informação, Brasília, v.2, n.1, p.89-103, jan./dez. 2009.

AUSUBEL, D. P. Educational psychology: a cognitive view. Nova York, Holt, Rienehart and Winston Inc., 1968.

AUSUBEL, D. P. Aquisição e retenção de conhecimentos: Uma perspectiva cognitiva, Lisboa: Editora Plátano, 2003.

BARDIN, L. Análise de conteúdo. Tradução: Luís Antero reto e Augusto Pinheiro. Edição e revista atualizada. Lisboa: Edições 70, LDA, 2009.

BELLUZZO, R. C. B. Construção de mapas: desenvolvendo competências em informação e comunicação. 2. ed. Bauru: Cá entre Nós, 2007. v. 1.111p.

BELLUZZO, R. C. B. O uso de mapas conceituais e mentais como tecnologia de apoio à gestão da informação e da comunicação: uma área interdisciplinar da competência em informação. Revista Brasileira de Biblioteconomia e Documentação: Nova Série, São Paulo, v.2, n.2, p.78-89, dez. 2006.

BESSA, V. H. Teorias da aprendizagem. Curitiba: IESDE Brasil S.A., 2008.

DERVIN, B. An overview of sense-making research: concepts, methods and results to date. In: INTERNATIONAL COMMUNICATIONS ASSOCIATION ANNUAL MEETING. Anais... Dallas, Texas, 1983. Disponível em: <http://communication.sbs.ohio-state.edu/sense-making/art/artdervin83.html>. Acesso em: 02 abril 2014.

DERVIN, B. Given a context by any other name: Methodological tools for taming the unruly beast. In: _ ; ForemanWernet, L.; Lauterbach, E. (Eds.). Sense-making methodology reader: Selected writings of Brenda Dervin Cresskill, NJ: Hampton Press, 2003. p. 111-132.

FEUERSTEIN, R. Instrumental enrichment: an intervention program for cognitive modifiability. Baltimore: University Park Press, 1980.

FUNDAÇÃO LUÍS EDUARDO MAGALHÃES (FLEM). Capacitação de lideranças comunitárias: uma experiência de gestão compartilhada para o combate à pobreza. Salvador: Flem, 2004.

FRISON, L. M. B. Auto-Regulação da Aprendizagem. Revista Ciência e Conhecimento, São Jerônimo, v. 2, p. 1-14, 2007.

GIL, A. C. Como elaborar projetos de pesquisa. São Paulo: Atlas, 1991.

GOMES, R. A análise de dados em pesquisa qualitativa. In: MINAYO, M. C. de S. Pesquisa social: teoria, método e criatividade. Petrópolis, RJ: Vozes, 1994, p. 67-80.

GONÇALVES, Marcio. Abordagem sense-making na Ciência da Informação: uma breve contextualização. Revista Digital de Biblioteconomia e Ciência da Informação, Campinas, v.9, n.2, p.1-11, jan. /jun. 2012.

HJøRLAND, Birger; ALBRECHTSEN, Hanne. Toward a new horizon in information science: domain-analysis. Journal of the American Society of Information Science, v.46, n.6, p. 400-425, 1995.

LEWIN, Kurt. Teoria de Campo em Ciência Social. São Paulo: Pioneira, 1965. 
LIMA, V. M. A. A organização do conhecimento no domínio da Ciência da Informação: o mapa conceitual e terminológico como instrumento referencial para o ensino e a pesquisa. InCID: Revista de Ciência da Informação e Documentação, Ribeirão Preto, v. 4 , n. 1 , p. $26-48$, jan./jun. 2013

MARTINS, Ana A. L. Mediação informacional: uma perspectiva a partir do campo social da informação. In: ENCONTRO NACIONAL DE PESQUISA EM CIÊNCIA DA INFORMAÇÃO, 14., 2013, Florianópolis. Anais... Florianópolis: UFSC, 2013.

MOREIRA, M. A.; MASINI, E. F. S. Aprendizagem significativa: a teoria de David Ausubel. São Paulo: Centauro, 2001.

NASCIMENTO, Denise M.; MARTELETO, Regina M. A informação construída nos meandros dos conceitos da teoria social de Pierre Bordieu. DataGramaZero: Revista de Ciência da Informação, Porto Alegre, v.5, n.5, out. 2004.

NOVAK, J. D.; GOWIN, B. Aprender a aprender. 2. ed. Lisboa: Plátano, 1999.

PELIZZARI, A.; et al. Teoria da aprendizagem significativa segundo Ausubel. Revista de Psicologia, Educação e Cultura, Curitiba, v.2, n.1, p.37-42, jul. 2001 - jul. 2002.

PIAGET, J. Discours du directeur du Bureau international d'éducation. In: TREIZIEME CONFERENCE INTERNATIONALE DE L'INSTRUCTION PUBLIQUE. Procès-verbaux et recommandations. Genebra: Bureau international d'éducation, 1950.p. 3536.

QUEIROZ, M. I. P. de. Variações sobre a técnica de gravador no registro de informação viva. São Paulo: T.A. Queiroz, 1991. (Biblioteca básica de ciências sociais. Série 2. Textos; v.7).

SOUZA, N. A. de; BORUCHOVITCH, E. Mapas conceituais: estratégia de ensino/aprendizagem e ferramenta avaliativa. Educação em Revista, Belo Horizonte, v.26, n.03, p.195-218, dez. 2010.

THIOLLENT, M. Pesquisa-ação nas organizações. São Paulo: Atlas, 1997.

THIOLLENT, M. Metodologia da pesquisa-ação. São Paulo: Cortez, 2000

TORRES, Márcia Zampieri. Situações-problema como recurso de avaliação de competências no Enem. In: Ministério da Educação. (Org.). Eixos cognitivos do Enem, Brasília, 2007, p. 31-53.

TRIBUS, Myron. Bridging in Both Directions. 2001. Disponível em: <http://www.feuersteintraining.co.uk/pdf/Bridging.pdf>. Acesso em: 20 março 2014. 


\section{Dados dos autores}

Maria Giovanna Guedes Farias

Professora do Programa de Pós-Graduação em Ciência da Informação da Universidade Federal do Ceará. Doutora em Ciência da Informação pela UFBA.

mgiovannaguedes@gmail.com

\section{Gabriela Belmont de Farias}

Professora do Programa de Pós-Graduação em Ciência da Informação da Universidade Federal do Ceará. Doutora em Ciência da Informação pela Unesp.

gabriela belmont@yahoo.com.br

Recibido - Received: 2016-01-21

Aceitado - Accepted: 2016-06-14

\section{(c) $)$ EY}

This work is licensed under a Creative Commons Attribution 4.0

United States License.

\section{ULLS DDof}

This journal is published by the University Library System of the University of Pittsburgh as part of its D-Scribe Digital Publishing Program and is cosponsored by the University of Pittsburgh Press. 